\title{
RESPOSTA DA CULTURA DO MILHO A MODOS DE APLICAÇÃO E DOSES DE FÓSFORO, EM ADUBAÇÃO DE MANUTE NÇÃO(1)
}

\author{
R. M. PRADO ${ }^{(2)}$, F. M. FERNANDES ${ }^{(3)} \&$ C. G. ROQUE ${ }^{(2)}$
}

\begin{abstract}
RESUMO
Os modos de adubação fosfatada mais estudados na cultura do milho são relacionados com a aplicação a lanço e a localizada no sulco de semeadura. No entanto, existe a possi bilidade da aplicação intermediária, em sulco duplo, que pode aumentar a fração do solo fertilizada e a eficiência da adubação. Com o objetivo de avaliar os efeitos de modos de aplicação e de doses de fertilizante fosfatado em adubação de manutenção, foi realizado este presente trabalho em Latossolo Vermelho-E scuro, na região do Triângulo Mineiro, em Uberaba (MG), com a cultura do milho, no período de outubro de 1995 a abril de 1996. Os tratamentos foram constituídos pelos modos de aplicação do adubo fosfatado (superfosfato tri plo), a lanço, sulco si mples e sulco duplo, e pelas doses de 0; 45,0; 67,5; 90,0; 112,5 e 135,0 kg ha-1 de $\mathrm{P}_{2} \mathrm{O}_{5}$. As doses de $P$ foram estimadas, tomando por base $0 ; 0,50 ; 0,75 ; 1,00 ; 1,25 ; 1,50$ vêzes a dose recomendada para a adubação de manutenção, $90 \mathrm{~kg} \mathrm{ha}^{-1}$ de $\mathrm{P}_{2} \mathrm{O}_{5}$. Verificou-se que: 0 uso de doses crescentes de $P$ aumentou a produção de grãos de milho; os modos de aplicação do adubo fosfatado em sulco si mples e sulco duplo foram mais eficientes que a lanço; dentre os modos de aplicação, destacou-se a aplicação em sulco duplo; o teor foliar de $\mathbf{P}$ variou de 2,1 a 2,4; 2,1 a 2,7 e de 2,1 a 2,9 g kg-1, respectivamente, para a aplicação a lanço, em sulco simples e em sulco duplo. 0 incremento na produção do mi lho foi de 0,45 a 3,04 t ha-1 no sulco simples e de 0,21 a 4,4 t ha-1 no sulco duplo.
\end{abstract}

Termos de indexação: modos de adubação, superfosfato triplo, sulco simples, sulco duplo, lanço, cerrado.

(1) Trabalho apresentado na XXIII Reunião Brasileira de Fertilidade do Solo e Nutrição de Plantas, 11 a 16 de Outubro de 1998 , Caxambu (MG). Recebido para publicação em março de 2000 e aprovado em outubro de 2000.

(2) Doutorando do Departamento de Solos e Adubos, Faculdade de Ciências Agrárias e Veterinárias, Universidade do Estado de São Paulo - UNESP. Via de acesso Prof. Paulo Donato Castellane $s / n^{\circ}$, CEP 14870-000 J aboticabal (SP). Bolsista da FAPESP. E-mail: rmprado@fcav.unesp.br

(3) Professor do Departamento de Ciência do Solo e Engenharia Rural, Faculdade de Engenharia de IIha Solteira, UNESP. Caixa Postal 31, CEP 15385-000 Ilha Solteira (SP). E-mail: maximino@agr.feis.unesp.br 


\title{
SUMMARY: EFFECTS OF FERTILIZER PLACEMENT AND LEVELS OF PHOSPHORUS ON FOLIAR PHOSPHORUS CONTENT AND CORN YIELD
}

\begin{abstract}
The most commonly studied phosphorus fertilizer placements in maize crop are scattering and furrow - local ized. However, doublefurrow intermediary application is al so possible and may increasethefertilized soil fraction and fertilization efficiency. This research was carried out to eval uatethe effects of fertilizer placement and doses of phosphorus fertilizer under maintainancefertilization of a corn crop, in a Dark-Red Latosol, in Triângulo Mineiro, Uberaba (MG, Brazil), from October 1995 to April 1996. The treatments consisted of the following fertilizer placements (triple superphosphate): broadcasting, single furrow and doubl efurrow and thefol lowing doses of $0 ; 45.0 ; 67.5 ; 90.0 ; 112.5$ and $135.0 \mathrm{~kg} \mathrm{ha}^{-1}$ of $\mathrm{P}_{2} \mathrm{O}_{5}$. Doses of $\mathrm{P}$ wereestimated based on $0 ; 0.50 ; 0.75 ; 1.00 ; 1.25 ; 1.50$ timethe dosereccomended for maitainancefertilization, $90 \mathrm{~kg} \mathrm{ha}^{-1}$ of $\mathrm{P}_{2} \mathrm{O}_{5}$. It was found out that the use of increasing $P$ doses increased corn grain yield; the phosphorus fertilizer placements in singl e furrows and double furrows were more efficient than broadcasting; doublefurrow application was the most oustanding mode of placement; fol iar P content varied from 2.1 to 2.4; 2.1 to 2.7 and from 2.1 to $2.9 \mathrm{~g} \mathrm{~kg}^{-1}$, respectively, for broadcasting, singl efurrows and doubl efurrows. Corn yield increased from 0.45 to $3.04 \mathrm{t} \mathrm{ha}^{-1}$ for singl e furrows and from 0.21 to $4.4 \mathrm{t} \mathrm{ha}^{-1}$ for doublefurrows.
\end{abstract}

Index terms: fertilization placements, triple superphosphate, single furrow, double furrow, scattering, cerrado.

\section{INTRODUÇÃO}

Os L atossol os da região do cerrado normal mente apresentam baixo teor de fósforo disponível, conforme sua natureza mineralógica e reação ácida (Lopes, 1983), razão por que, em tais circunstâncias, a adubação fosfatada torna-se necessária para garantir a produtividade máxima econômica das culturas. Nesse sentido, têm-se realizado pesquisas sobre modos de apl icação de fósforo no solo, buscando melhorar sua eficiência na cultura do milho (Anghinoni, 1992).

Os modos de adubação mais discutidos na literatura são a aplicação a lanço e a localizada no sulco de semeadura. A adubação a lanço faz com que praticamente $100 \%$ do fertilizante fosfatado entre em contado com o solo, possibilitando el evada adsorção de $\mathrm{P}$ e reduzindo o aproveitamento desse el emento pela planta. Por outro lado, para diminuir a adsorção, utiliza-se a aplicação local izada do adubo fosfatado e, como conseqüência, pequena porção do sistema radicular entra em contato com o fósforo proveniente do adubo (Malavolta, 1981). Nesse aspecto, tornam-se necessários estudos de modos de aplicação intermediários, a fim deaumentar a fração de solo fertilizado, sem incorrer em avanços significativos da adsorção, o que refletiria em maior eficiência de uso do adubo fosfatado pelas plantas (Yost et al., 1979).

Apesar de serem escassos os trabalhos na literatura a respeito do modo de aplicação intermediário da adubação fosfatada de manutenção, em condições de campo, existem relatos com resposta positiva na cultura do milho (Vasconcellos et al., 1986). Entretanto, recomenda-se apenas a forma localizada, no sulco de semeadura, colocando-se o fertilizante a $5 \mathrm{~cm}$ ao lado e de 5 a $10 \mathrm{~cm}$ de profundidade (Coel ho, 1997), não existindo, nas áreas comerciais, o modo de adubação intermediário.

Nesse contexto, objetivou-se avaliar a resposta do milho ao modo intermediário de aplicação do adubo fosfatado, em sulco duplo, comparado-o com a aplicação em sul co simples e a lanço, em diferentes doses de adubação de manutenção.

\section{MATERIAL E MÉTODOS}

O experimento foi conduzido no município de Uberaba (MG), na Fazenda N ossa SenhoraA parecida, num LatossoloVermel ho-Escuro distrófico, dassificado segundo a EMBRAPA (1988). A análises química e física do solo encontram-se no quadro 1 . O delineamento experimental foi em parcelas subdivididas, com as parcel as principais organizadas em blocos, com quatro repetições. As parcel as foram constituídas pelos modos de aplicação do adubo fosfatado (sulco duplo, sulco simples e a lanço), enquanto as subparcelas, pelas doses de adubação fosfatada: $0 ; 0,50 ; 0,75 ; 1,00 ; 1,25 ; 1,50$ vez a dose recomendada para a adubação de manutenção, $90 \mathrm{~kg} \mathrm{ha}^{-1} \mathrm{deP}_{2} \mathrm{O}_{5}$ (CF SEMG, 1989), perfazendo um 


\section{Quadro 1. Atributos químicos e físicos do Latossolo Vermelho-E scuro, na profundidade 0-20 cm}

\begin{tabular}{|c|c|c|c|c|c|c|c|c|c|c|}
\hline $\begin{array}{c}\text { pH } \mathrm{H}_{2} \mathrm{O} \\
(1: 2,5)\end{array}$ & MO & $\mathbf{P}^{(1)}$ & $K^{(1)}$ & $\mathbf{A I}^{(2)}$ & $\mathrm{Ca}^{(2)}$ & $\mathbf{M g}^{(2)}$ & $\mathbf{H}+\mathrm{Al}^{(3)}$ & SB & $\mathbf{T}$ & $\mathbf{v}$ \\
\hline \multirow[b]{2}{*}{6,2} & $\mathrm{~g} \mathrm{~kg}^{-1}$ & $\mathrm{mg} \mathrm{dm}^{-3}$ & 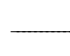 & 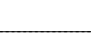 & $-n$ & $d_{c} \mathrm{dm}^{-3}$ & 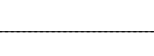 & - & - & - \\
\hline & 25 & 5 & 0,9 & 0 & 30 & 7 & 21 & 37,9 & 58,9 & 64 \\
\hline \multicolumn{3}{|c|}{ Areia grossa } & \multicolumn{2}{|c|}{ Areia fina } & \multicolumn{3}{|c|}{ Silte } & \multicolumn{3}{|c|}{ Argila(4) } \\
\hline \multicolumn{3}{|c|}{60} & \multicolumn{3}{|c|}{20} & \multicolumn{2}{|c|}{260} & \multicolumn{3}{|c|}{660} \\
\hline
\end{tabular}

(1) $\mathrm{P}$ e $\mathrm{K}$ extraídos pelo Mehlich-1. (2) $\mathrm{Ca}, \mathrm{Mg}$ e Al extraído com $\mathrm{KCl} 1 \mathrm{~mol} \mathrm{~L}{ }^{-1}$; MO determinado pelo método Walkley \& Black (Defelipo \& Ribeiro, 1981). ${ }^{(3)} \mathrm{H}+\mathrm{Al}$ extraído com acetato de cálcio 0,5 mol L-1; pH 7,0 (Raij \& Quaggio, 1983). (4) Silte e argila, método da pipeta (EMBRAPA, 1979).

total de 18 tratamentose 72 unidades experimentais. Utilizou-se, como fonte de $\mathrm{P}$, o superfosfato triplo granulado $\left(44 \%\right.$ de $\left.\mathrm{P}_{2} \mathrm{O}_{5}\right)$.

O preparodesolo constou de uma gradagem pesada (grade de 14 discos x 32"), seguida de escarificação (escarificador com nove hastes vibratórias) até $30 \mathrm{~cm}$ de profundidade e, ainda, de duas gradagens de nivelamento. $\mathrm{Na}$ área do experimento, a cultura anterior foi a soja decicl otardio, durante cinco anos agrícolas consecutivos.

A adubação básica consistiu da aplicação lanço, incorporada na camada de 0-20 cm de profundidade, trinta dias antes da semeadura, de $115 \mathrm{~kg} \mathrm{ha}^{-1} \mathrm{deK}_{2} \mathrm{O}$ na forma de cloreto de potássio, com o objetivo de saturar $4 \%$ da CTC com potássio; $300 \mathrm{~kg} \mathrm{ha}^{-1}$ degesso agrícola, e $40 \mathrm{~kg} \mathrm{ha}^{-1}$ deóxidos silicatados ( $\mathrm{B}=2,5 \%$; $\mathrm{Cu}=1,0 \% ; \mathrm{Fe}=3,0 \% ; \mathrm{Mn}=3,0 \% ; \mathrm{Mo}=0,1 \%$ e $\mathrm{Zn}=$ $15,0 \%)$.

A semeadura foi realizada com a semeadoraadubadora modelo J umil Magnum $2800 \mathrm{com}$ plataforma de cinco metros, equipada com quatro unidades semeadoras para a distribuição das sementes e oito unidades adubadoras para a distribuição do fertilizante fosfatado com discos duplos.

A aplicação do fertilizante fosfatado constou dos seguintes tratamentos: (a) sulco simples (modo convencional): refere-seà unidade adubadora ao lado da linha da semente, posicionada a $5 \mathrm{~cm}$ ao lado e abaixo da semente. Com esta adubação, a faixa fertilizada no fundo do sulco foi de aproximadamente $4,5 \mathrm{~cm}$ de largura, ao passo que o espaçamento da cultura adotado foi de $0,90 \mathrm{~m}$, o que corresponde aproximadamentea $5 \%$ da fração horizontal do sol o; (b) sulco duplo: consistiu de dois sulcos da unidade adubadora em cada linha da unidade semeadora, posicionada a $5 \mathrm{~cm}$ a cada lado e abai xo da semente, de modo que a faixa fertilizada passou a ser o dobro da anterior, perfazendo aproximadamente $10 \%$ da fração do solo; (c) a lanço: aplicação em área total, manualmente e com posterior incorporação a aproximadamente $15 \mathrm{~cm}$ de profundi dade com grade niveladora (32 discos $\times 22$ "), perfazendo $100 \%$ da fração do sol o fertilizado.

As parcelas foram constituídas de quarenta eoito, eas subparcelas, de oito linhas, espaçadas de 0,90 m, com $20 \mathrm{~m}$ de comprimento, perfazendo a área total de 864 e $144 \mathrm{~m}^{2}$, respectivamente. Manteve-se a distância de $8 \mathrm{~m}$ entre blocos (repetições) para a realização das manobras das máquinas.

Utilizou-se o híbrido triplo BR 3123, produzido pela Embrapa Milho e Sorgo (Sete Lagoas, MG), recomendado para a região em estudo, semeado em 16 de outubro de 1995. A densidade populacional de semeadura foi cal culada com baseem 55.000 plantas estabelecidas por hectare.

A adubação de cobertura foi realizada mecanicamente, 22 dias após a semeadura (quinta fol ha exposta), com $400 \mathrm{~kg} \mathrm{ha}^{-1}$ da fórmula 20-00-10, incorporada a $5 \mathrm{~cm}$ de profundidade e posicionada lateralmente a $20 \mathrm{~cm}$ das plantas.

$\mathrm{Na}$ época do florescimento, 65 dias após a semeadura, amostrou-se o terço médio de 10 fol has por tratamento e por repetição. A fol ha amostrada correspondeu àquela abaixo e oposta à inflorescência feminina, de acordo com Malavolta (1992). As amostras obtidas foram secas em estufa com circulação forçada de ar a $65^{\circ} \mathrm{C}$, pesadas e moídas, determinando-se, a seguir, o fósforo, de acordo com o método descrito por Bataglia et al. (1983).

Para obter o produção de grãos, foram col hidas, em 20 de abril de 1996, as quatro linhas centrais de cada subparcela, perfazendo uma área útil de $72,0 \mathrm{~m}^{2}$, e, em seguida, foram col hidas amostras para 
corrigir a umidade dos grãos para $0,13 \mathrm{~kg} \mathrm{~kg}^{-1}$. Além disso, determinou-se o fator $\mathrm{P}$, que é o fator de utilização do $\mathrm{P}\left(\mathrm{kg} \mathrm{ha}^{-1}\right.$ de $_{2} \mathrm{O}_{5} /$ aumento de produção em kg ha-1) (Tyney \& Weeb, 1946), sendo o aumento da produção obtido a partir da produção de grãos no nível zero de P (testemunha).

Os dados obtidos foram submetidos à análise de variância, teste de Tukey e análise de regressão (Gomes, 1990).

\section{RESULTADOS E DISCUSSÃO}

No quadro 2, são apresentados um resumo da análise de variância dos dados de produção de grãos de milho e o teor foliar de P, para modos de aplicação de fósforo, doses de fósforo e para a interação modo de aplicação versus doses de fósforo. $\mathrm{E} m$ ambas as variáveis estudadas, houve efeito significativo para o modo de aplicação, para as doses de P e para a interação modo de aplicação versus doses de fósforo, com exceção dada para a interação na variável teor foliar de P.

O efeito do modo de aplicação do $P$ indicou que a produção de grãos de milho no sulco duplo foi superior à do sulco simples, e este maior que a aplicação a lanço (Figura 1). A interação observada indica que os modos de aplicação não tiveram o mesmo comportamento de acordo com as doses de $P$ utilizadas na produção degrãos de mil ho. A interação iniciou-se na dose de $67,5 \mathrm{~kg} \mathrm{P}_{2} \mathrm{O}_{5}$, e os modos de aplicação localizados foram superiores ao modo a lanço, na produção de grãos, e, somentea partir dessa dose, houve di ferença entreas apl icações localizadas, destacando-se o sulco duplo (Figura 2).

Portanto, os resultados obtidos evidenciaram superioridade da aplicação do adubo fosfatado de manutenção em sulco duplo, indicando que, utilizando esse modo de aplicação da adubação fosfatada, em sol os com baixo teor de P-disponível e nos sol os de cerrado em geral, a adsorção do fósforo é mi nimizada e, ao mesmo tempo, o contato do adubo fosfatado com o sistema radicular das plantas é maximizado. Ressalta-se que o volume de solo explorado pelas raízes de uma planta é, em média, $1 \%$ do volume do solo (Bray, 1954). Resultados semelhantes com aplicação do fósforo pelo modo intermediário foram obtidos por Barber (1977), Vasconcellos et al. (1986) eAnghinoni (1992).

Cabe salientar que o efeito favorável do sulco duplo na cultura do milho deveu-se, além da interação favorável P-solo, discutida anteriormente, à interação P-planta. Segundo Barber (1995), com a aplicação localizada do adubo fosfatado no milho, ocorre maior desenvolvimento radicular na área adubada, e o grau de proliferação depende da quantidade de fósforo aplicada e do seu nível inicial no solo. Anghinoni \& Barber (1980) demonstraram haver estresse nutricional quando parte do sistema radicular do milho estava adequadamente suprida de fósforo.

Nessa mesma linha, Novais et al. (1985) observaram que o $\mathrm{P}$ se acumula de maneira desuniforme na fol ha do milho, em conseqüência de sua disponibilidadelimitada a apenas uma parte do sistema radicular, como ocorre na aplicação localizada. Todavia, quando fornecido em ambos os

Quadro 2. Resumo da análise de variância dos dados de produção de grãos de milho e teor foliar de P, para os fatores estudados

\begin{tabular}{lccc}
\hline Causa de variação & GL & Produção de grão & Teor foliar de P \\
\hline & & & F \\
Blocos & 3 & $0,62^{\text {n.s }}$ & $12,37^{* *}$ \\
Modo de aplicação (M) & 2 & $90,07^{* *}$ & - \\
Resíduo (a) & 6 & - & $18,74^{* *}$ \\
(Dose de fósforo - D) & $(5)$ & $\left(78,56^{* *}\right)$ & $1,20^{\text {ns }}$ \\
(M x D) & $(10)$ & $0,74^{\text {ns }}$ & - \\
D dentro de M1 & 5 & $34,12^{* *}$ & - \\
D dentro de M2 & 5 & $76,68^{* *}$ & - \\
D dentro de M3 & 5 & - & - \\
Resíduo (b) & 45 & 8,4 & 8,6 \\
C.V. (a) (\%) & & 7,1 & 8,2 \\
C.V. (b) (\%) & & &
\end{tabular}

ns, * e **: Não significativo ( $P>0,05)$, significativos a $\mathrm{P}<0,05$ e $\mathrm{P}<0,01$, respectivamente. 


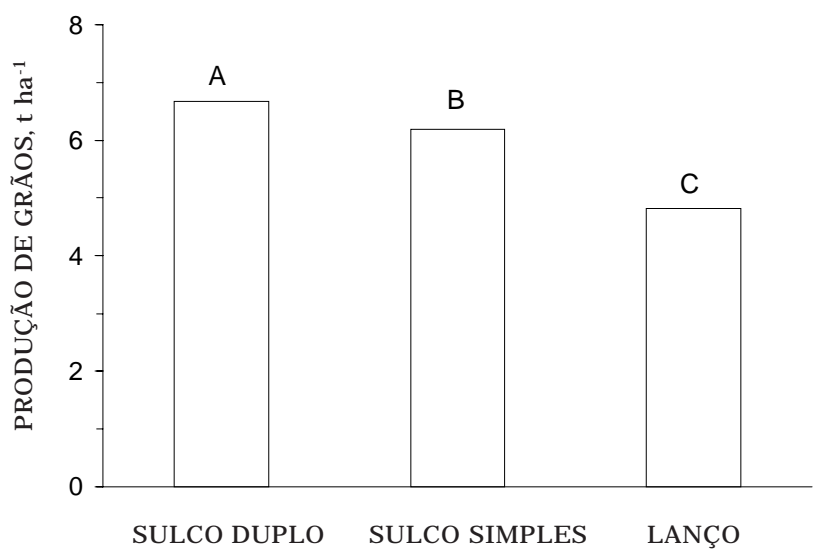

Figura 1. Efeito dos modos de aplicação do fertilizante fosfatado em sulco duplo, sulco simples e a lanço na produção de grãos da cultura do milho (dados médios de seis doses de fósforo e quatro repetições). Colunas com a mesma letra não diferem estatisticamente entre si pelo teste de Tukey $(P<0,05)$.

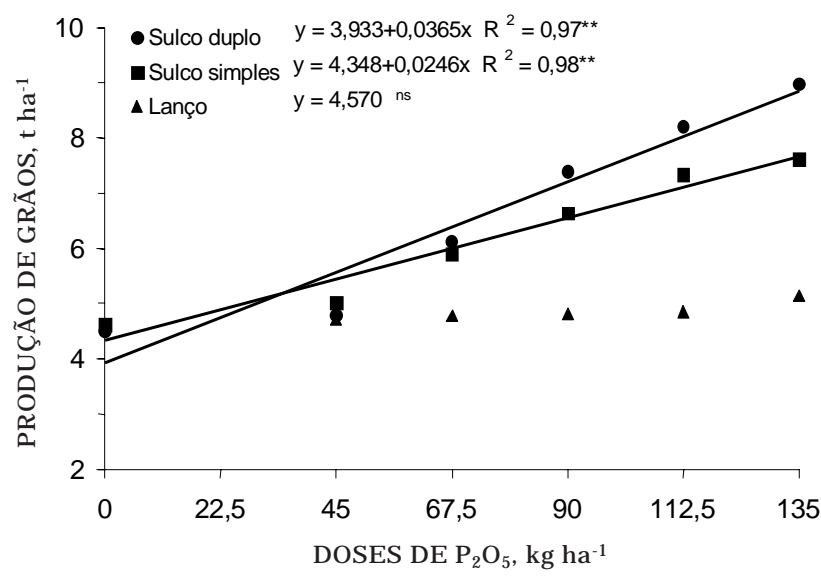

Figura 2. Efeito dos modos de aplicação do fertilizante fosfatado em sulco simples e sulco duplo na produção de grãos da cultura do milho.

lados da planta, a distribuição de $\mathrm{P}$ interna é uniformemente favorecida. Essa compartimentalização de $\mathrm{P}$ na planta, em resposta ao contato do elemento com apenas parte do sistema radicular, indica haver limitação na redistribuição interna de P na planta (Alves et al., 1999) e pode ser explicada pelo tipo de vascularização entre fol has e raízes do milho (Stryker et al., 1974).

As doses de fósforo em adubação de manutenção, em geral, influenciaram significativamente a produção de grãos de milho (Quadro 2), o que está de acordo com diversos trabalhos relatados na literatura (N eptune et al., 1982; Souza et al., 1998).
A quantidade de fósforo recomendada para a aplicação no sul co de semeadura, considerando o teor do nutriente no solo, $90 \mathrm{~kg} \mathrm{ha}^{-1}$ de $\mathrm{P}_{2} \mathrm{O}_{5}$, mostrou-se insuficiente para proporcionar as mai ores produções de grãos no experimento, que foram de 7,25 t ha-1, para a dose de $135 \mathrm{~kg} \mathrm{ha}^{-1}$ de $\mathrm{P}_{2} \mathrm{O}_{5}$, e de $6,80 \mathrm{t} \mathrm{ha}^{-1}$, para a dose de $112,5 \mathrm{~kg} \mathrm{ha}^{-1}$ de $\mathrm{P}_{2} \mathrm{O}_{5}$. A dose de $90 \mathrm{~kg} \mathrm{ha}^{-1}$ proporcionou produção de 6,29 t ha-1 de grãos de milho, a qual está de acordo com a recomendação da CFSEM G (1989), tanto para a dose de $\mathrm{P}$, quando o teor de $\mathrm{P}$ no solo for muito baixo, como para a produtividade esperada. Em outros países, em lavouras de alta produtividade, as doses máximas recomendadas para a aplicação no sulco de semeadura variam de 120 a $250 \mathrm{~kg} \mathrm{ha}^{-1}$, segundo Gamboa (1980), citado por Cantarella (1993).

Analisando os modos de aplicação e as doses de fósforo, isoladamente (Quadro 2), nota-se que, na aplicação a lanço, não houve efeito significativo de doses. Conforme era esperado, esse efeito, provavelmente, deveu-seà alta adsorção de $\mathrm{P}$ nesse solo, uma vez quea aplicação a lanço levou a um maior contato do P com a fase sólida do solo, favoreci do pel o el evado teor de argila (Quadro 1). Entretanto, na aplicação em sulco simples e sulco duplo, houve efeito significativo das doses deP, uma vez que ofenômeno da adsorção foi reduzido graças ao menor contato do P com o solo.

Com basenas equações da figura 2, estima-se que, em média, para cada kg de $\mathrm{P}_{2} \mathrm{O}_{5}$ aplicado, tem-se incremento de 36,5 e 24,6 kg de mil ho em relação à testemunha, para os modos de aplicação em sulcos duplo esimples, respectivamente. Desse modo, podese inferir que as estimativas de incrementos da produção com a adubação fosfatada podem ser aumentadas em $48 \%$, quando se opta pela aplicação em sulco duplo, em relação ao modo convencional em sulco simples.

O efeito não-significativo das doses de fósforo estudadas neste experimento, com aplicação a Ianço (Figura 2), deveu-se, provavel mente, além da maior adsorção já menci onada, às quantidades utilizadas, ou seja, à maior dose de $\mathrm{P}_{2} \mathrm{O}_{5}$ utilizada, que foi de $135 \mathrm{~kg} \mathrm{ha}^{-1}$. A recomendação da CF SE MG (1989), em adubação corretiva (aplicação a lanço), é de 4 kg ha-1 de $\mathrm{P}_{2} \mathrm{O}_{5}$ para cada $10 \mathrm{~g} \mathrm{~kg}^{-1}$ de argila presente no solo, quando o $\mathrm{P}$ disponível apresentar menos que $5 \mathrm{mg} \mathrm{dm}^{-3}$. Portanto, no caso deste experimento e seguindo a recomendação, a dose de $\mathrm{P}$ seria de $264 \mathrm{~kg} \mathrm{ha}^{-1}$ de $_{2} \mathrm{O}_{5}$, queé praticamente o dobro dos $135 \mathrm{~kg} \mathrm{ha}^{-1}$ utilizados.

Estes resultados indicam, ainda, quea aplicação do adubo fosfatado em sulco duplo mostrou efeito menor em dose baixa (45 kg ha-1 de $\mathrm{P}_{2} \mathrm{O}_{5}$ ) e maior na dose recomendada (90 kg ha-1 de $\mathrm{P}_{2} \mathrm{O}_{5}$ ) e, principalmente, acima dela, podendo-se inferir que esse tipo de aplicação de P é mais vantajoso para lavouras de al ta tecnologia, enquanto para lavouras 
de baixa tecnol ogia, que utilizam doses de $\mathrm{P}$ baixas ou inferiores às recomendadas para a região, a adubação local izada, do modo convencional, em sulco simples é mais vantajosa.

Pelos teores foliares de fósforo, observou-se que o modo de aplicação a lanço provocou as menores alterações, como era esperado, variando de 2,1 a $2,4 \mathrm{~g} \mathrm{~kg}^{-1}$ diferindo-se significativamente do sulco duplo, com P foliar variando de 2,1 a 2,9, que, por sua vez, não diferiu do sulco simples, que foi de 2,1 a $2,7 \mathrm{~g} \mathrm{~kg}^{-1}$ (Quadro 3). O aumento do teor foliar de , considerando a adubação fosfatada local izada, pode explicar o aumento da produção de grãos, tendo em vista a relação positiva entre o teor foliar de P e a produção de grãos (Figura 3).

No entanto, verificou-se que o teor foliar de P foi menor que $2,5 \mathrm{~g} \mathrm{~kg}^{-1}$ na aplicação a Ianço e nas aplicações localizadas em doses menores que $90 \mathrm{~kg} \mathrm{ha}^{-1}$ de $\mathrm{P}_{2} \mathrm{O}_{5}$ (Quadro 3), resultando em menores produções de grãos, enquanto as aplicações localizadas em doses superiores a $90 \mathrm{~kg} \mathrm{ha-1}$ apresentaram teores foliares acima desse nível e, conseqüentemente, as maiores produções de grãos (Figura 3).

É possível que as menores produções de grãos estejam associadas aos teores foliares de $\mathrm{P}$ menores que $2,5 \mathrm{~g} \mathrm{~kg}^{-1}$, uma vez que esses teores são considerados baixos na interpretação de Malavolta et al. (1997), que consideram adequada a faixa de 2,5 a 3,5 $\mathrm{g} \mathrm{kg}^{-1}$. Entretanto, para Cantarella et al. (1996), a faixa de teores de P considerada adequada é de 2,0 a $4,0 \mathrm{~g} \mathrm{~kg}^{-1}$.

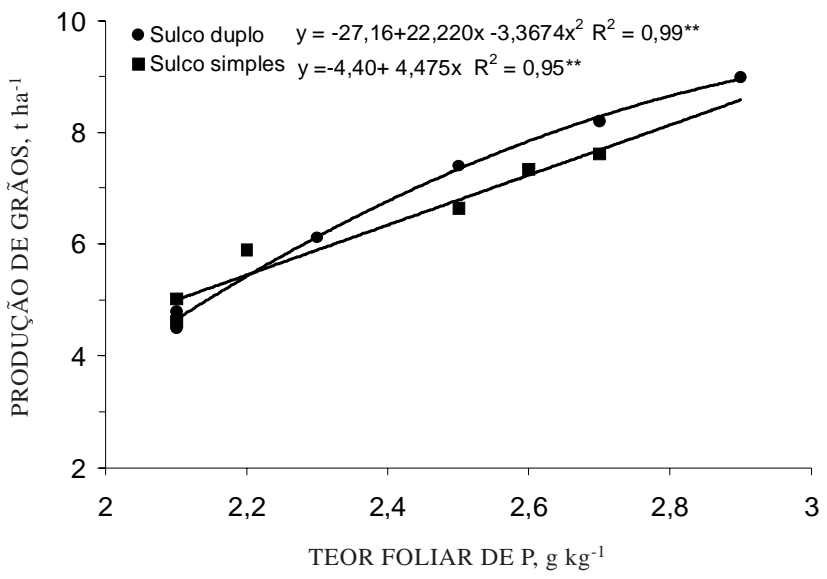

Figura 3. Relação do teor foliar de $P$ e a produção de grãos de milho, considerando os modos de aplicação em sulco duplo e sulco simples.

Acredita-se que a diferença entre as faixas adequadas de $P$ nas folhas observadas por esses autores seja devida ao uso de diferentes cultivares, uma vez que Machado et al. (1999) observaram grande variabilidade entre genótipos e cultivares de milho para a eficiência do uso de fósforo.

Os teores foliares de N, K, Ca, Mg eS (dados não apresentados) não foram influenciados significativamente pelos modos e pelas doses da adubação fosfatada. Na literatura, são escassos os trabalhos que estudaram os efeitos dos modos de adubação

Quadro 3. Teor foliar de P, incremento de produção de milho e fator de utilização do fósforo, consi derando os tratamentos

\begin{tabular}{|c|c|c|c|c|c|c|c|c|c|}
\hline \multirow{3}{*}{$\begin{array}{c}\text { Dose } \\
\text { de } \mathrm{P}_{2} \mathrm{O}_{5}\end{array}$} & \multicolumn{9}{|c|}{ Modo de aplicação } \\
\hline & \multicolumn{3}{|c|}{ Lanço } & \multicolumn{3}{|c|}{ Sulco simples } & \multicolumn{3}{|c|}{ Sulco duplo } \\
\hline & $\begin{array}{l}\text { Teor } \\
\text { de } P(1)\end{array}$ & $\begin{array}{l}\text { Aumento da } \\
\text { produção(2) }\end{array}$ & Fator $\mathbf{P}^{(3)}$ & $\begin{array}{l}\text { Teor } \\
\text { de P }\end{array}$ & $\begin{array}{l}\text { Aumento da } \\
\text { produção }\end{array}$ & Fator $\mathbf{P}$ & $\begin{array}{l}\text { Teor } \\
\text { de P }\end{array}$ & $\begin{array}{l}\text { Aumento da } \\
\text { produção }\end{array}$ & Fator $\mathbf{P}$ \\
\hline $\mathrm{kg} \mathrm{ha}^{-1}$ & $\mathrm{~g} \mathrm{~kg}^{-1}$ & $\mathrm{t} \mathrm{ha}^{-1}$ & & $\mathrm{~g} \mathrm{~kg}^{-1}$ & $\mathrm{t} \mathrm{ha}^{-1}$ & & $\mathrm{~g} \mathrm{~kg}^{-1}$ & $\mathrm{t} \mathrm{ha}^{-1}$ & \\
\hline 45,0 & 2,1 & 0,13 & 0,346 & 2,1 & 0,45 & 0,100 & 2,1 & 0,21 & 0,210 \\
\hline 67,5 & 2,1 & 0,20 & 0,337 & 2,2 & 1,32 & 0,051 & 2,3 & 1,54 & 0,044 \\
\hline 90,0 & 2,3 & 0,24 & 0,375 & 2,5 & 2,06 & 0,044 & 2,5 & 2,82 & 0,032 \\
\hline 112,5 & 2,3 & 0,28 & 0,402 & 2,6 & 2,76 & 0,041 & 2,7 & 3,63 & 0,031 \\
\hline 135,0 & 2,4 & 0,57 & 0,237 & 2,7 & 3,04 & 0,044 & 2,9 & 4,40 & 0,031 \\
\hline Média(4) & $2,2 \mathrm{~B}$ & & & $2,4 \mathrm{AB}$ & & & $2,4 \mathrm{~A}$ & & \\
\hline
\end{tabular}

(1) na testemunha, sem $P$, teor foliar $=2,1 \mathrm{~g} \mathrm{~kg}^{-1}$. (2) Obtido em relação a média de produção de grãos $\left(4,58 \mathrm{t}\right.$ ha $\left.{ }^{-1}\right)$ na dose zero de $P$ (ausência de aplicação de $\mathrm{P}$ ) considerando os três modos de aplicação. ${ }^{(3)}$ Fator $\mathrm{P}$ : fator de utilização do $\mathrm{P}\left(\mathrm{kg}\right.$ ha ${ }^{-1}$ de $\mathrm{P}_{2} \mathrm{O}_{5} /$ aumento de produção em $\left.\mathrm{kg} \mathrm{ha}^{-1}\right)$. ${ }^{(4)}$ Letras iguais não diferenciam entre si pelo teste de Tukey $(P<0,05)$. 
fosfatada nos teores dos nutrientes, além do $P$. Entretanto, Alves et al. (1999), estudando o fornecimento de $P$ em parte do sistema radicular do milho, em vasos, observaram que não houve diferença significativa na absorção dos outros nutrientes ( $\mathrm{N}, \mathrm{Ca}$ e $\mathrm{Mg}$ ) em um dos experimentos; no outro, houve redução na acumulação desses nutrientes pela parte aérea do milho.

De qualquer forma, os resultados destetrabalho evidenciam que os fatores mais importantes para explicar a produção de grãos do milho, o modo de aplicação do fósforo no solo e, conseqüentemente, o teor fol iar foram mais importantes que as alterações na absorção de outros nutrientes.

Cabesalientar, ainda, quea variaçãono teor foliar de $P$, especialmente pela aplicação localizada da adubação fosfatada da testemunha para maior dose de $P$, atingiu o máximo de $0,8 \mathrm{~g} \mathrm{~kg}^{-1}$, para um aumento considerável da produção de grãos demilho $\left(4,4 t^{\text {ha-1 }}\right)$. As menores variações do $P$ das fol has de acordo com as doses podem ter recebi do contribuição do efeito concentração e diluição, provocado pelo menor emaior crescimento das plantas, uma vez que, embora não se disponha de resultados quantitativos, notou-se que o desenvol vimento inicial do milho foi mais I ento nas parcel as com aplicação das doses zero (testemunha) e $45 \mathrm{~kg}$ de $\mathrm{P}_{2} \mathrm{O}_{5} \mathrm{ha}^{-1}$, em comparação com as parcelas com as doses maiores de adubo.

$\mathrm{Na}$ literatura, resultados semelhantes foram obtidos por Neptune et al. (1982), que encontraram incremento no P foliar do milho deapenas $0,83 \mathrm{~g} \mathrm{~kg}^{-1}$, resultando em um aumento da produção de grãos de milho de mais de 3,0 t ha-1. O teor foliar de $\mathrm{P}$ passou de $2,05 \mathrm{~g} \mathrm{~kg}^{-1}$ (ausência de adubação fosfatada e produção de 3,98 t ha-1) para 2,88 $\mathrm{g} \mathrm{kg}^{-1}$. Souza et al. (1998) também observaram, em um ensai o em condições de campo, que apenas uma variação de $P$ foliar ainda menor de $0,5 \mathrm{~g} \mathrm{~kg}^{-1}$ resultou em incremento significativo na produção de milho $\left(4,8\right.$ t ha $\left.^{-1}\right)$.

No quadro 3, verifica-se, ainda, que esse aumento no teor foliar de $\mathrm{P}$ nas aplicações localizadas acarretou um incremento na produção, que variou de 0,45 a 3,04 t ha-1, na aplicação em sul co simples, e de 0,21 a 4,40 t ha-1, na aplicação em sulco duplo.

Outro aspecto observado foi o fator de utilização deP (Quadro 3), que, segundoTyney \& Webb (1946), pode ser definido como a quantidade, em unidade denutriente, exigida para produzir aumento de uma unidade de produção. Os dados evidenciaram que o aumento da dose deP diminuiu ofator de utilização nos dois modos de aplicação de fósforo, ou seja, aumentou a eficiência do adubo fosfatado aplicado. Entretanto, esta eficiência foi mel hor quando o adubo fosfatado foi aplicado em sulco duplo, confirmando os dados das figuras 1 e2. Neptune et al. (1982), em um experimento com diferentes doses deadubo fosfatado, encontraram ofator de utilização deP igual a 0,051, valor esse próximo ao encontrado neste trabal ho.
Em síntese, o presente estudo revelou uma alternativa para a adubação fosfatada de manutenção em sulco duplo, que pode ser vantajosa, mesmo em áreas que estejam sendo exploradas há mais de cinco anos, mas que ainda apresentam limitado teor de P no solo. Por outro lado, os resultados deste trabal ho reforçaram a tese de que uma das prováveis causas da produtividadelimitada do milho no cerrado esteja associada ao estresse nutricional, decorrente da fertilização fosfatada em apenas um lado da planta, ou seja, em sul co simples.

\section{CONCLUSÕES}

1. A aplicação de doses crescentes de fósforo aumentou a produção de grãos de milho.

2. O teor foliar de $\mathrm{P}$, considerando o modo de aplicação, foi superior ao teor a lanço, porém semel hante ao do sulco simples.

3. Os modos de aplicação do adubo fosfatado em sulco simples e sulco duplo foram mais eficientes que a aplicação a Ianço, porém o incremento na produção do milho foi superior no sulco duplo em relação ao sulco simples.

\section{AGRADE CIME NTOS}

À Agropecuária Nossa Senhora Aparecida de U beraba (MG), por ceder o espaço físico, e ao Prof. Dr. William Natale, pelas sugestões no manuscrito.

\section{LITERATURA CITADA}

ALVES, V.M.C.; MAGALHÃES, J.V.; VASCONCELLOS, C.A.; NOVAIS, R.F.; BAHIA FILHO, A.F.C.; FRANÇA, G.E.; OLIVEIRA, C.A.\& FRANÇA, C.C.M.Acúmulo denitrogênio e de fósforo em plantas de milho afetadas pelo suprimento parcial de fósforo nas raízes. R. Bras. Ci. Solo, 23:299-305, 1999.

ANGHINONI, I. Uso de fósforo pelo milho afetado pela fração de solo fertilizada com fosfato solúvel. R. Bras. Ci. Solo, 16:349-53, 1992.

ANGHINONI,I.\& BARBER, S.A. Phosphorus influx and growth characteristics of corn roots as influenced by phosphorus supply. Agron. J ., 22:685-688, 1980.

BARBER, S.A. Mecanismos de absorção de fósforo sob condições de estresse ambiental. In: SIMPÓSIO INTERNACIONAL SOBRE ESTRESSE AMBIENTAL, 1., Belo Horizonte. 1992, Anais. Sete Lagoas, Empresa Brasileira de Pesquisa Agropecuária, 1995. p.233-237. 
BARBER, S.A. Placement of phosphate and potassium for increased efficiency. Solutions, 21:24-25, 1977.

BATAGLIA, O.C.; FURLANI, A.M.C.; TEIXEIRA, J.P.F.; FURLANI, P.R. \& GALLO,J.R. Métodos de análise química de plantas. Campinas, Instituto Agronômico de Campinas, 1983. 48p. (Bol etim técnico, 78)

BRAY, R.H. A nutrient mobility concept of soil-plant relationships. Soil Sci., 78:9-22, 1954.

CANTARELLA, H. Calagem e adubação do milho. In: BULL, L. T. \& CANTARELLA, H., eds. Cultura do milho: fatores que afetam a produtividade. Piracicaba, 1993. p.147-196.

CANTARELLA, H.; RAIJ , B.van \& CAMARGO, C.E.O. Cereais. In: RAIJ , B.van; CANTARELLA, H.; QUAGGIO, J.A. \& FURLANI, A.M.C., eds. Recomendações de adubação e calagem para o estado de São Paulo. 2.ed. Campinas, Instituto Agronômico de Campinas, 1996. p.45-71.

COELHO,J .L.D. Critérios de sel eção de máquinas eimplementos agrícolas para a cultura do milho. In: FANCELLI, A.L. \& DOURADO-NETO, D., eds. Tecnologia da produção de milho. Piracicaba, Publique, 1997. p.1-9.

COMISSÃO DE FERTILIDADE DO SOLO DO ESTADO DE MINAS GERAIS - CFSEMG. Recomendações para o uso de corretivos e fertilizantes em Minas Gerais (4a aproximação) Lavras, 1989. 159p.

DEFELIPO, B.V. \& RIBEIRO,A.C.Análisequímica do solo. Viçosa, Universidade Federal de Viçosa, 1981. 17p. (Boletim Extensão, 29)

EMPRESA BRASILEIRA DE PESQUISA AGROPECUÁRIA EMBRAPA. Serviço Nacional de Levantamento e Conservação de Solos. Manual de modos de análise de solos. Rio de J aneiro, 1979. 620p.

EMPRESA BRASILEIRA DE PESQUISA AGROPECUÁRIA EMBRAPA. Serviço Nacional de Levantamento e Conservação de Solos. Sistema brasileiro de classificação de solos. Rio de J aneiro, 1988. 122p.

GOMES, F.P. Curso de estatística experimental. 13.ed. São Paulo Nobel, 1990. 467p.

LOPES, A.S. Sol os sob "cerrado": características, propriedades e manejo. Piracicaba, POTAFÓS, 1983. 162p.
MACHADO, C.T.T.; GUERRA, J.G.M.; ALMEIDA, D.L. \& MACHADO, A.T. Variabilidade entre genótipos de milho para eficiência no uso de fósforo. Bragantia, 58:109-124, 1999.

MALAVOLTA, E. ABC da análise de solo e fol has: amostragem, interpretação e sugestões de adubação. São Paulo, Agronômica Ceres, 1992. 124p.

MALAVOLTA, E. Manual de química agrícola: adubos eadubação. 3ed. São Paulo, Agronômica Ceres, 1981. 594p.

MALAVOLTA, E.; VITTI, G.C. \& OLIVEIRA, S.A. Avaliação do estado nutricional das plantas: princípios e aplicações. 2ed. Piracicaba, Associação Brasileira para Pesquisa da Potassa e do Fosfato, 1997. 319p.

NEPTUNE,A.M.L.; NAKAGAWA, J .;SCOTTON, L.C. \& SOUZA, E.A. Efeitos de doses não equidistantes de $N, P, K$, nas concentrações destes macronutrientes na folha e na produção do milho (Zea mays L.). An. ESALQ, 39:917-941, 1982.

NOVAIS, R.F.; FERREIRA, R.P.; NEVES, J .C.L. \& BARROS, N.F. Absorção de fósforo e crescimento do milho com sistema radicular parcialmente exposto à fonte de fósforo. Pesq. Agropec. Bras., 20:749-754, 1985.

RAIJ, B. van. \& QUAGGIO, J.A. Métodos de análise de solo. Campinas, Instituto Agronômico de Campinas, 1983. 31p. (Bol etim Técnico, 81)

SOUZA, E.C.A.; COUTINHO, E.L.M.; NATALE, W. \& BARABOSA, J.C. Respostas do milho à adubação com fósforo e zinco. Pesq. Agropec. Bras., 33:1031-1036, 1998.

STRYKER, R.B.; GI LLIAM, J.W. \& J ACKSON, W.A. Nonuniform transport of phosphorus from single roots to the leaves of Zea mays. Physiol. Plant., 30:231-239, 1974.

TYNEY,E.H.\& WEEB,J.W.The relation of corn yields to nutrient balance as revealed by leaf analysis. J. Am. Soc. Agron., 38:173-185, 1946.

VASCONCELLOS, C.A.; SANTOS, H.L.; FRANÇA, G.E.; BAHIA FILHO, A.F.C. \& PITTA, G.V.E. Doses, modos de aplicação e fontes de fosfatos na produção de milho. Pesq. Agropec. Bras., 21:245-254, 1986.

YOST, R.S.; KAMPRATH, E.J .; LOBATO, E. \& NADERMAN, G. Phosphorus response of corn on Oxisol as influenced by rates and placement. Soil Sci. Soc. Am. J ., 43:338-343, 1979. 